\title{
The Relationship between Advanced Manufacturing Technologies and ISO 9001 Certified Enterprises of Mechanical Engineering and Metalworking in Latvia
}

\author{
G. Civcisa \\ Institute of Mechanical Engineering, Faculty of Mechanical Engineering, \\ Transport and Aeronautics, Riga Technical University \\ Viskalu 36A, LV-1006, Riga, Latvia \\ Email: guna.civcisa@rtu.lv
}

\begin{abstract}
In this study, the relationship between advanced manufacturing technologies (AMTs) and ISO 9001 certification was analyzed. The purpose was to examine the most used AMTs in enterprises of mechanical engineering and metalworking (MEM) sector in Latvia. A literature review was conducted first to determine what technologies are currently considered to be advanced in manufacturing. This article gives detailed information of six types of AMTs, which according to the survey are most frequently applied by MEM sector enterprises in Latvia. The information for this analysis is obtained from the database collected by the Latvian Association of Mechanical Engineering and Metalworking Industries (MASOC). Paper also presents the usage of these technologies by enterprise size class (micro, small, medium and large size). The results of the comparative analysis are discussed, taking into account ISO 9001 Quality Management System (QMS) certification and non-certification factor, respectively. The data sample is based on more than 100 enterprises from MEM sector where the use of AMTs was identified. The findings showed that the most often a computer numerical control (CNC) and computer-aided design (CAD) are used by enterprises of MEM in Latvia. The hypothesised relationship was supported by results which showed that in enterprises that do not have ISO 9001 certification CAD technologies are used in $13 \%$ of cases, while enterprises with ISO 9001 in $20 \%$ of cases, respectively. The CNC is used in $62 \%$ of cases by enterprises without ISO 9001 and in $76 \%$ of cases having ISO 9001 certificate. From above, it could be concluded that in enterprises in which a QMS certified according to the ISO 9001 is introduced, these two above mentioned technologies are used more frequently (7-8 \% points more).
\end{abstract}

Keywords: ISO 9001; advanced manufacturing technologies; mechanical engineering.

\section{INTRODUCTION}

Mechanical engineering is among traditional manufacturing sectors in Latvia, which mainly focused on the export. Before the financial crisis (2005-2007) and after the stabilisation of economic situation (2008-2010) it makes a significant contribution to the manufacturing industry and all national economy in general [1]. The output of the metalworking industry in 2012 was almost $40 \%$ higher than before the crisis, but the growth rates in the production of machinery and equipment were very moderate. In 2015 , production volumes in the machinery and equipment industry increased almost by $8 \%$ and also the metalworking industry contributed significantly to the total growth of the manufacturing [2]. 
According to Rao [3] manufacturing is the backbone of any industrialised nation and the level of manufacturing activates indicates the economic health of any country. In a broader sense, manufacturing is a process by which the raw material is transformed into products. Thus, it includes product design, selection of raw material and the sequence of different processes [4]. Today's manufacturing includes a wide set of interrelated activities that not only related to product design, selection of materials and production, but also with the processes of planning, documentation, quality assurance, management, and marketing [3]. It seems that for sustainable development the only way in today's manufacturing world is properly selected and used AMTs. It could play a crucial role for the growth of the organisation [5], but not exclusive, attention could also possibly be directed to continuous innovation aspect [6]. An empirical survey that was focused on the automotive industry in developing countries emphasis, that without the adaptation of AMTs they are facing the risk of falling out of competition due to manufacturing performance [7]. AMTs are designed to make the manufacturing process more agile and flexible [8]. Again, another study suggests that before investing in AMTs, companies need to fully understand these technologies [9]. Moreover, it is important to understand that investments in AMTs technologies are significant also for small and medium enterprises (SMEs) [10].

Mechanical engineering companies have also considered the application of quality systems as a preference for successful work in global markets. ISO 9001 quality management systems standard is the most well-known quality management system of the ISO 9000 family. The implementation of ISO 9001 is often considered by enterprises when entering foreign markets to expand export. Currently, the latest edition of this standard is ISO 9001:2015 and this is the fifth edition. This standard contains the requirements for quality management systems. More than one million and one hundred and six thousand organisations run their business by the certified quality management system [11].

The previously mentioned observations led the author to consider what if any relation is between the AMTs and the most widely implemented quality management system given the importance of MEM for the Latvian economy. In this respect, the objective was to examine the potential impact of ISO 9001 on the use of AMTs in MEM sector enterprises. To justify these observations, an overview of the literature was carried out to ascertain whether the previous studies have found a relationship between the certified ISO 9001 system and any performance parameters.

A literature review was conducted to determine the spread of ISO 9001 in the MEM sector in Latvia, then to determine previous studies that have examined the potential impact of quality management system standard on performance parameters of enterprises as well as AMTs impact on manufacturing performance and finally, to identify the types of AMTs.

\section{ISO 9001 Quality Management System}

A comparative analysis was done initially, to identify how many enterprises in Latvia in general and in MEM sector having implemented a certified QMS. Table 1 presents a comparative study of ISO 9001 standard implementation in MEM industry and widespread in Latvian and neighbouring countries. It is following from the calculation data, that Norway is a leader about the implementation of ISO 9001 certified QMS in MEM sector enterprises (about $13 \%$ of the total in the country). A similar situation is found in two other neighbouring countries, almost $13 \%$ of Finnish and $11 \%$ of 
Estonian MEM sector enterprises are certified according to ISO 9001. The data in Table 1 shows that implementation of this standard is lower in Latvia (6\% of total) and Lithuania (4\% of total) in comparison with other neighbouring countries.

Table 1. Implementation of ISO 9001 in Latvia and neighbouring countries, by the number of issued certificates.

\begin{tabular}{lccc}
\hline Country & $\begin{array}{c}\text { Basic metal and fabricated } \\
\text { metal products }\end{array}$ & $\begin{array}{c}\text { Machinery and } \\
\text { equipment }\end{array}$ & $\begin{array}{c}\text { ISO 9001 total } \\
\text { (in numbers) }\end{array}$ \\
\hline Latvia & 62 & 9 & 1115 \\
Lithuania & 40 & 10 & 1238 \\
Estonia & 90 & 33 & 1131 \\
Finland & 207 & 127 & 2596 \\
Norway & 195 & 133 & 2467 \\
Sweden & 288 & 124 & 4316 \\
\hline
\end{tabular}

Source: Calculation based on the ISO Survey.

The results of the empirical research on the extent of ISO 9001 certificates, broken down by industrial sectors on the world scale show that MEM enterprises constituting altogether $20 \%$ of the total number of certified companies and have moved forward to the leading five industrial sectors [12].

\section{Impact of ISO 9001 implementation}

The impact of ISO 9001 certification on enterprise performance has been investigated by several authors. The results from the literature review were contradictory. According to the findings of Koc, even if differences in some manufacturing parameters were found, he argues that it cannot be concluded that this relationship is caused only by certification [13]. Similar observations were found when the impact of ISO 9000 certification on product and process innovation performance was examined by Terziovski and Guerrero [14]. This is also in line with some others, like Feng et al., who found that ISO 9000 certification has a positive and significant effect on operational performance, but a weak positive effect on business performance [15]. Cai and Jun state further, that the firm's operations performance may be facilitated if ISO 9000 is implemented with other quality improvement initiatives [16]. A similar finding has been reported by Bayo-Moriones et al., that one of quality improvement initiatives, like the EFQM model contributes over ISO 9001 regarding the implementation of innovative practices [17].

In what concerns main benefits, Terlaak and King analysis showed that certified facilities grow faster after certification with ISO 9000 [18]. Lo et al. found that ISO 9000 certified firms showed continuous improvement and significantly improves the time-based efficiency [19]. Sharma in his study explores the association between ISO 9000 certification and financial performance and found that ISO 9000 certification does bring benefit to the firm [20]. It was found by Iwaro and Mwasha that there is a direct relationship between ISO 9001 certification and improvement of employee performance [21]. Another study by Santos et al. revealed that internal organisation and continuous assessment through internal audits had been the main benefits that Portuguese SMEs have gained with QMS certification [22]. Furthermore, it is observed by Danesh et al., 
that a competitive advantage is achieved by introducing a certified QMS according to the requirements of ISO 9001 in manufacturing companies [23].

Although many authors found a difference between certified and non-certified enterprise, it should be emphasised that it is closely related and depends on parameters being measured. This conclusion is supported by the work of Manders et al., which conclude that there is a list of factors that might affect ISO 9001 certification on product innovation [24].

\section{Advanced Manufacturing Technologies}

The impact of AMTs on manufacturing performance has been analysed in previous studies. Swink and Nair found that there is a relationship between AMTs adaption and manufacturing performance [25] and Spanos and Voudouris found that further adoption of AMTs is closely related with quality and flexibility capabilities [26], besides Koc and Bozdag also found the positive impact on various manufacturing parameters to SMEs and relationship between AMTs, manufacturing parameters, and firm performance were found [10]. Ocampo et al. found that the use of AMTs gives a positive effect on the manufacturing competitiveness [27]. It is also found by Singh et al., that the adoption of suitable AMTs can help SMEs to improve their performance and provide a competitive edge [28]. The analysis of surveys from 60 enterprises has shown that the main benefit of investing in AMTs is to gain better market shares [29].

According to the literature review, AMTs are divided into several categories: manufacturing, administrative and design AMTs [7], or into hard and soft technologies [30]. The term AMTs is used to describe a variety of technologies, which primarily utilize computers to control, track, or monitor manufacturing activities, either directly or indirectly [31]. The examination up to eight main areas of manufacturing systems [32] can be found in the literature.

It was found that up to 45 different types of AMTs are listed in the literature. The set of technologies that can be considered to be AMTs in this study is based on a literature review by several authors [9,33-39]. The AMTs which are very frequently mentioned are: computer-aided design (CAD), robots, computer-aided manufacturing (CAM), computer numerical control (CNC), flexible manufacturing systems (FMS) and manufacturing resource planning (MRPII). Frequently mentioned AMTs are: just-intime manufacturing (JIT), statistical process control (SPC), computer-aided engineering (CAE), computer-integrated manufacturing (CIM). The AMTs that are occasionally mentioned are: fast/rapid prototyping, laser technologies, electronic data interchange (EDI), local area networks (LAN), wide computer networks (WAN) and lean manufacturing. There are also AMTs that have been mentioned very rarely: electrical discharge machining (EDM), wire-cut and three-dimensional coordinate measuring (CMM). The study analyses the types of technologies identified in the literature and those on which the data were available MASOC database.

The literature review gives the important contribution to the development of this study under two main contents. The findings show that in several studies the relationship between certified ISO 9001 system and various performance measures has been found and validated. Furthermore, those investigations have indicated that the implementation of AMTs has a positive impact on manufacturing performance.

Based on literature review and author's observations of the potential impact of ISO 9001 on the use of AMTs, a research hypothesis was defined - there is a tendency 
to use more AMTs in enterprises where the ISO 9001 certified quality system is introduced.

\section{METHODOLOGY}

The evaluation was carried out in the following five steps such as 1) identifying enterprises according to economic activity; 2) selecting of enterprises certified according to the ISO 9001 standard requirements; 3) classification of enterprises by size-classes; 4) determination of the most frequently used AMTs and 5) statistical treatment of data.

Evaluation of mechanical engineering and metalworking sector was started by identifying enterprises belonging to this sector according to the type of their economic activities. Interpretations of European and national level organisations are compared regarding classification of MEM sector. The size of the sector is determined by analysing two organisations at European level, one of these includes the European umbrella organisation the European Engineering Industries Association (ORGALIME), representing interests of Mechanical, Electrical \& Electronic, Metalworking \& Metal Articles Industries and the second includes national level organisation, namely the MASOC.

Based on these results it is stated that in this study the MEM sector covers three divisions of section C (manufacturing) of NACE Rev.2 [40]. According to the following groupings of NACE Rev. 2 these divisions are:

a) 24 Manufacture of basic metals

b) 25 Manufacture of fabricated metal products, except machinery and equipment

c) 28 Manufacture of machinery and equipment n.e.c.

Data for situation analysis were gained from the MASOC database [41] where extended information on enterprises of MEM sector is available. Information on each observed enterprise is included in the database, which is made to systematise the selected data according to the following parameters: title, a number of employees, NACE Rev. 2 code, certificates and used manufacturing technologies. As a result of data selection and processing (taking into consideration limits defined by MEM sector), it was stated that 104 enterprises registered at MASOC meet the criteria of this research and may be used for further analysis. The scope of these 104 selected enterprises was divided as follows: the manufactures of basic metals including nine enterprises, the manufactures of fabricated metal products, except machinery and equipment including 69 enterprises and the manufactures of machinery and equipment including 26 enterprises.

The companies were classified according to its size group by the SME classification provided in Commission Recommendation 2003/361/EC [42]. The size class data of enterprises presented in this article are based on a definition relating to the number of persons employed. The breakdown is as follows: an enterprise belongs to a micro class if it employs fewer than ten persons, those who employs fewer than 50 persons fall within the small class. All enterprises having fewer than 250 persons are medium-sized while those with 250 or more people are defined as the large enterprises.

The present article has some limitations. First, it focuses only on specific three divisions of manufacturing (based on NACE Rev. 2), selected within a line of interest of this study. Second, in the sample, it was possible to include only enterprises registered in the MASOC database, because it contains the most comprehensive information related to issued certificates and technologies used in each enterprise. Third, the deeper 
analysis was conducted for the limited number of AMTs (CAN and CNC), because other technologies are used rarely by enterprises contained in the sample. Forth, the data sets contain only binary variables (enterprises have or do not have ISO 9001 certificate and any of technologies), which did not allow to use the correlation analysis. Instead, other more suitable statistical methods have been applied (e.g. calculations of similarity coefficients).

\section{DATA ANALYSIS AND RESULTS}

The practical implications of this paper include a detailed overview of the most used AMTs and the most active MEM sector enterprises in their application by size classes in Latvia. Such research results could be useful for practitioners with interest in the ISO 9001.

Enterprises of MEM are assessed given certified and uncertified QMS factor, and an effect of this factor on the application of AMTs is determined. The analysis covers 104 enterprises where 119 cases of AMTs use were stated. From the range of technologies, being used by Latvian enterprises that are listed in the MASOC database, data on six types of technologies which according to the review of the literature are regarded as AMTs, are being used for further analysis.

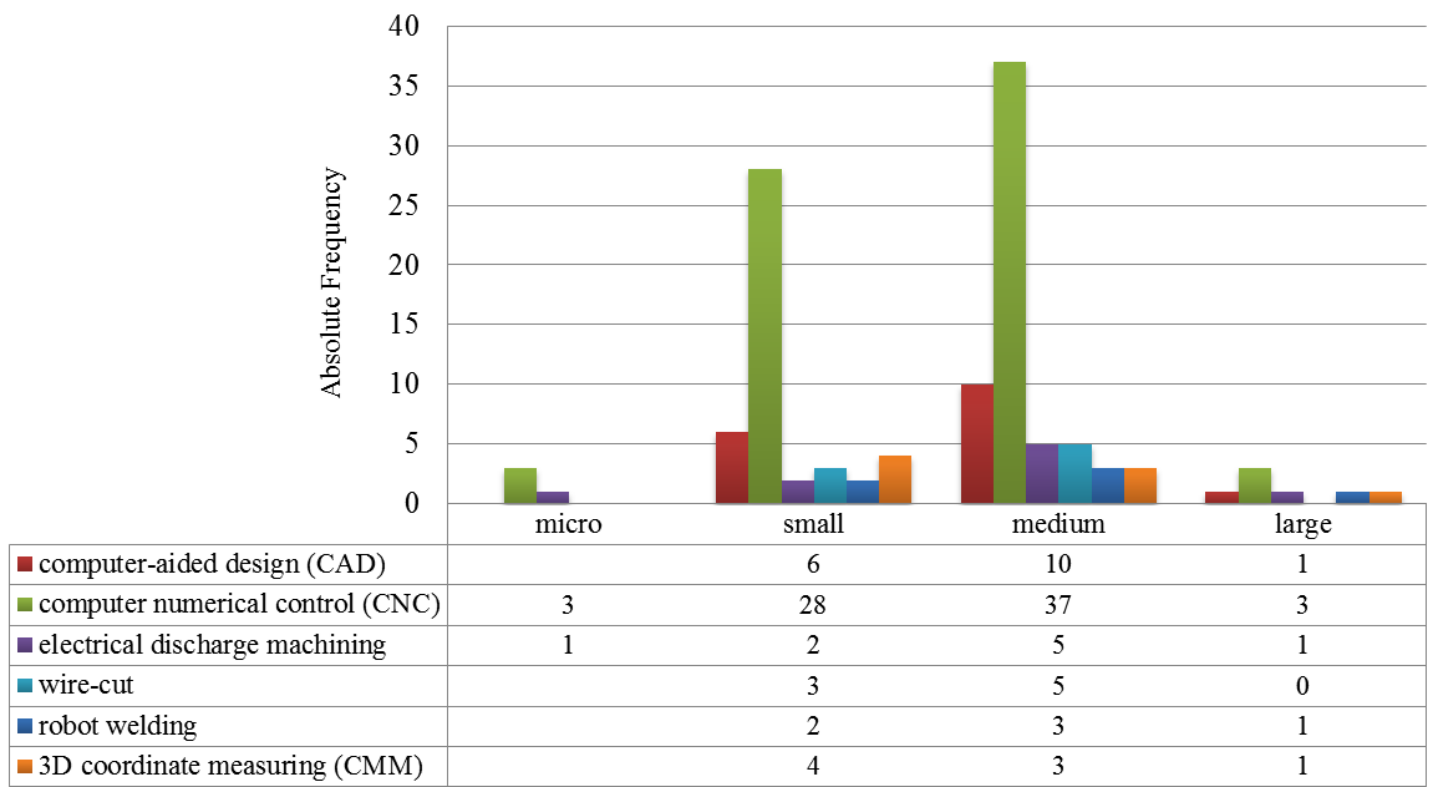

Figure 1. The frequency of use of AMTs broken down by enterprise size classes.

Absolute frequency of application of all six AMTs types broken down by enterprise size classes is given in Figure 1. When analysing data by enterprises' sizeclasses, it was established that most of all AMTs are being used in small (53\%) and medium (38\%) enterprises of MEM. When comparing the obtained data with the number of enterprises, they do not differ essentially in groups of small and medium enterprises (the proportion is similar). The situation is inversely proportional in the groups of micro and large enterprises; if the number of microenterprises is numerically larger than the number of large enterprises in general, then AMTs they use least (in the amount of $3 \%$ ) of all four enterprise size-classes. 
The analysis of the application of AMTs shows that from these six AMTs types in the enterprises of MEM most often they use computer numerical control (CNC), i.e. $60 \%$. The second most often used type of AMTs is a computer-aided design (CAD); frequency of use constitutes $14 \%$. Other four types (electrical discharge machining, wire-cut, robot welding, CMM) are being used nine times less than $\mathrm{CNC}$ on average.

Comparative analysis was carried out by enterprise size classes in MEM sector to find out whether enterprises having implemented a certified QMS according to the ISO 9001 use AMTs more. The analysis covered two most often used technologies $\mathrm{CAD}$ and CNC. Enterprises of MEM, considering their size-classes, are grouped according to two factors: "ISO 9001" - enterprise has a certified quality management system and "No"- enterprise has non-certified quality management system (Figure 2).

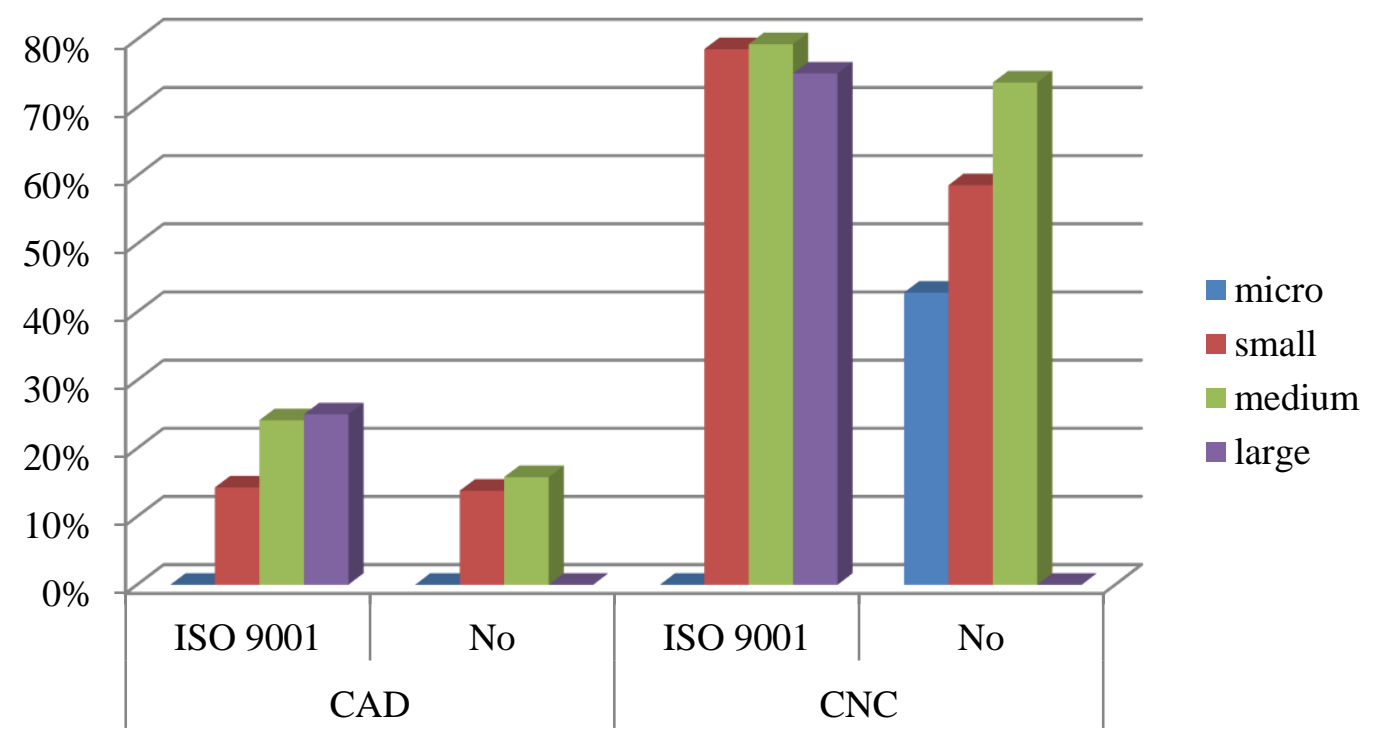

Figure 2. Frequency of AMTs application within the context of ISO 9001.

The results of the analysis on the extent of use of CAD and CNC technologies in all enterprise groups in general and separately by enterprise size-classes differ. In the group of large enterprises (Figure 2) all enterprises have a certificate of conformity to the requirements of ISO 9001, of which CAD is being used by $25 \%$ and CNC $-75 \%$ of enterprises. In the group of medium enterprises CAD is being used by $24 \%$ and CNC - by $79 \%$ of enterprises with ISO 9001 certificate of conformity, but in enterprises that do not have ISO 9001 certification CAD technology is being used by $16 \%$ and CNC $74 \%$. In the group of small enterprises, CAD technologies are being used proportionally equal between enterprises that have and do not have ISO 9001 certificate $-14 \%$ respectively. CNC is being used by $79 \%$ of small enterprises having ISO 9001 and $59 \%$ - without ISO 9001 certificate of conformity. It was established that in the group of microenterprises CAD technologies are not used; regarding the use of CNC comparative results cannot be given (78\% of microenterprises do not have ISO 9001 certificate).

Findings from MEM sector analysis show that large (100\% in the sample) and medium size (60\% in the sample) enterprises have chosen ISO 9001 compliance certificate; it is more frequently than small and micro-sized enterprises. Very similar results have given the analysis of AMTs usage by size classes of enterprises (including 
both certified and noncertified by ISO). The CAD technologies have been applied by large companies $(25 \%)$ most frequently; medium-sized companies are following by 21 $\%$. Small and micro-sized companies are using CAD technologies more rarely (14\% and $0 \%$ respectively). The CNC technologies have been spread out widely in the group of medium-sized companies (77\%), following by large companies (75\%).

Further, the statistical calculation was conducted because the study intended to quantify the measure of the relationship between AMTs and ISO 9001 certified enterprises in MEM sector. Since all data are binary in this study, the calculation of the Pearson correlation coefficient is not well suited for this particulate case. Thus another method was applied. The similarity coefficients (Dice and Jaccard) were used for the statistical interpretation of the data [43]. Dice similarity coefficient (DSC) was utilised to examine the similarity and diversity of two data sets. Accordingly, for CAD and ISO 9001, the DSC is 0.3 and 0.6 for CNC and ISO 9001, respectively. The same pattern of similarity shows the Jaccard similarity coefficient since CAD is used realty, the Jaccard similarity coefficient for ISO 9001 and CAD is rather low $(21.7 \%)$. Jaccard similarity coefficient for CNC and ISO 9001 is rather high $(80.4 \%)$. That means that the relationship between ISO and CNC is highly close (similarity is over $80 \%$ of the data set).

\section{CONCLUSION}

The article comprises in-depth evaluation of enterprises of MEM by analysing the extent of application of AMTs. The AMTs most widely used in the 104 enterprises of MEM in Latvia have been defined. Within the literature, up to 45 different types of AMTs were identified. The six most commonly used technologies of the enterprises in the sample were analysed broken down by enterprise size classes. To understand the effect of ISO 9001 certification on AMTs implementation, a structured database was used by both the technology used and the size of the enterprise. As a result of comparative analysis of the use of both technologies one can observe a tendency that $\mathrm{CAD}$ and $\mathrm{CNC}$ technologies, in general, are more used by enterprises having implemented a certified QMS according to the requirements of ISO 9001. Four and five AMTs types simultaneously are used only by two enterprises; besides both fall under the group of SMEs and both have ISO 9001 certification.

The frequent use of CNC mainly is related to productivity and competitiveness issues which play a crucial role in $\mathrm{n}$ nowadays manufacturing. The MEM sector in Latvia is not the exception by contributing significantly to the national economy. The $\mathrm{CNC}$ is the most applicable technology in manufacturing processes directly, while CAD technologies could be used for design proposes. Since manufacturing companies, in general, are more than development companies, this explains extensive use of CNC.

It also can be concluded that, according to the results of analysis based on ISO data, in the enterprises of MEM sector certification of QMS, evaluating conformity with ISO 9001 requirements is widely spread in the world and should characterised as high. There could be three main reasons what make enterprises consider introducing a QMS certified according to the ISO 9001. The first one is the market of the product, namely is the product intended for the internal or the external market. Two other reasons which have an impact on certification factor are the size of enterprise and costs for implementation and certification of QMS according to ISO 9001.

Future research might be focused in a perspective of green technologies and their effect on firms' performance. Following the recent study of Bai and Sarkis [44] on 
green manufacturing flexibility evaluation, the implementation of more environmentfriendly AMTs is becoming increasingly important globally due to environmental sustainability issues. Finally, it can be concluded that the green aspects concerning AMTs will become more and more relevant.

\section{ACKNOWLEDGEMENT}

The author would like to thank the Association of Mechanical Engineering and Metalworking Industries of Latvia for permission to use data.

\section{REFERENCES}

[1] Ministry of Economics Republic of Latvia. Economic Development of Latvia. Riga; 2011.

[2] Ministry of Economics of Republic of Latvia. Economic Development of Latvia. Riga; 2016.

[3] Rao RV. Advanced Modeling and Optimization of Manufacturing Processes : International Research and Development. Springer; 2011.

[4] Technical University Kosice F of MT. IRMA - Inter-Countries for Manufacturing Advancement, 2008, p 12.

[5] Nath S, Sarkar B. Performance Evaluation of Advanced Manufacturing Technologies: A De Novo Approach. Computers and Industrial Engineering 2017; 110: 364-378.

[6] Madonsela NS, Mukwakungu SC, Mbohwa C. Continuous Innovation as Fundamental Enabler for Sustainable Business Practices. Procedia Manufacturing 2017; 8(October 2016): 278-283.

[7] Bülbül H, Ömürbek N, Paksoy T, Bektaş T. An Empirical Investigation of Advanced Manufacturing Technology Investment Patterns: Evidence from a Developing Country. Journal of Engineering and Technology Management JET-M 2013; 30(2): 136-156.

[8] Kannan PK, Healey J. Service Customization Research: A Review and Future Directions. In: Demirkan H, Spohrer JC K V (ed). The Science of Service Systems. New York: Springer Science \& Business Media 2011; 297-324.

[9] Abdullah R, Hassan MG. Advanced Manufacturing Technology: The Perceived Impact on Producer's Value. The Asian Journal of Technology Management 2012; 5(1): 23-32.

[10] Koc T, Bozdag E. The Impact of AMT Practices on Firm Performance in Manufacturing SMEs. Robotics and Computer-Integrated Manufacturing 2009; 25(2): 303-313.

[11] ISO. The ISO Survey 2016. Geneve: ISO; 2017.

[12] ISO. ISO Survey 2015. Geneva: ISO; 2016.

[13] Koc T. The Impact of ISO 9000 Quality Management Systems on Manufacturing. Journal of Materials Processing Technology 2007; 186(1-3): 207-213.

[14] Terziovski M, Guerrero JL. ISO 9000 Quality System Certification and Its Impact on Product and Process Innovation Performance. International Journal of Production Economics 2014; 158: 197-207.

[15] Feng M, Terziovski M, Samson D. Relationship of ISO 9001:2000 Quality System Certification with Operational and Business Performance: A Survey in 
Australia and New Zealand-Based Manufacturing and Service Companies. Journal of Manufacturing Technology Management 2008; 19(1): 22-37.

[16] Cai S, Jun M. A Qualitative Study of the Internalization of ISO 9000 Standards: The Linkages among Firms' Motivations, Internalization Processes, and Performance. International Journal of Production Economics 2018; 196(May 2017): 248-260.

[17] Bayo-Moriones A, Merino-Díaz-De-Cerio J, Antonio Escamilla-De-León S, Mary Selvam R. The Impact of ISO 9000 and EFQM on the Use of Flexible Work Practices. International Journal of Production Economics 2011; 130(1): $33-42$.

[18] Terlaak A, King AA. The Effect of Certification with the ISO 9000 Quality Management Standard: A Signaling Approach. Journal of Economic Behavior and Organization 2006; 60(4): 579-602.

[19] Lo CKY, Yeung ACL, Cheng TCE. ISO 9000 and Supply Chain Efficiency: Empirical Evidence on Inventory and Account Receivable Days. International Journal of Production Economics 2009; 118(2): 367-374.

[20] Sharma DS. The Association between ISO 9000 Certification and Financial Performance. International Journal of Accounting 2005; 40(2): 151-172.

[21] Iwaro J, Mwasha A. The Effects of ISO Certification on Organization Workmanship Performance. Quality Management Journal 2012; 19(1): 53-67.

[22] Santos G, Mendes F, Barbosa J. Certification and Integration of Management Systems: The Experience of Portuguese Small and Medium Enterprises. Journal of Cleaner Production 2011; 19(17-18): 1965-1974.

[23] Yahya S, Danesh S, Hashemnia S, Khorramkhah H, Payman SJ. A Survey on the Effect of the Establishment of ISO 9001 on Achieving Competitive Advantage in Firms Manufacturing Products Included in Mandatory Standards Act of Guilan Province. International Research Journal of Applied and Basic Sciences 2012; 3(7): 1477-1484.

[24] Manders B, De Vries HJ, Blind K. ISO 9001 and Product Innovation: A Literature Review and Research Framework. Technovation 2016; 48-49: 41-55.

[25] Swink M, Nair A. Capturing the Competitive Advantages of AMT: DesignManufacturing Integration as a Complementary Asset. Journal of Operations Management 2007; 25(3): 736-754.

[26] Spanos YE, Voudouris I. Antecedents and Trajectories of AMT Adoption: The Case of Greek Manufacturing SMEs. Research Policy 2009; 38(1): 144-155.

[27] Ocampo JR, Hernández-Matías JC, Vizán A. A Method for Estimating the Influence of Advanced Manufacturing Tools on the Manufacturing Competitiveness of Maquiladoras in the Apparel Industry in Central America. Computers in Industry 2017; 87: 31-51.

[28] Singh B, Narain R, Yadav RC. Identifying Critical Barriers in the Growth of Indian Micro, Small and Medium Enterprises (MSMEs). International Journal of Business Competition and Growth 2012; 2(1): 84.

[29] Kumar S, Mital A, Pennathur A. Human Work Productivity: A Global Perspective. CRC Press; 2014.

[30] Small MH, Yasin MM. Developing a Framework for the Effective Planning and Implementation of Advanced Manufacturing Technology. International Journal of Operations \& Production Management 1997; 17(5): 468-489.

[31] Boyer KK, Leong GK, Ward PT, Krajewski LJ. Unlocking the Potential of Advanced Manufacturing Technologies. Journal of Operations Management 
1997; 15(4): 331-347.

[32] Esmaeilian B, Behdad S, Wang B. The Evolution and Future of Manufacturing: A Review. Journal of Manufacturing Systems 2016; 39: 79-100.

[33] Zhou H, Keong Leong G, Jonsson P, Sum CC. A Comparative Study of Advanced Manufacturing Technology and Manufacturing Infrastructure Investments in Singapore and Sweden. International Journal of Production Economics 2009; 120(1): 42-53.

[34] Percival JC, Cozzarin BP. Complementarities in the Implementation of Advanced Manufacturing Technologies. Journal of High Technology Management Research 2010; 21(2): 122-135.

[35] Hofmann C, Orr S. Advanced Manufacturing Technology Adoption - The German Experience. Technovation 2005; 25(7): 711-724.

[36] Krar SF, Gill A. Exploring Advanced Manufacturing Technologies. New York: Industrial Press; 2003.

[37] Llach Pagès J, Bikfalvi A, de Castro Vila R. The Use and Impact of Technology in Factory Environments: Evidence from a Survey of Manufacturing Industry in Spain. The International Journal of Advanced Manufacturing Technology 2010; 47(1-4): 181-190.

[38] Mohamed NMZN, Khan M. Decomposition of Manufacturing Processes: A Review. International Journal of Automotive and Mechanical Engineering 2012; 5(January-June): 545-560.

[39] Gupta K, editor. Advanced Manufacturing Technologies: Modern Machining, Advanced Joining, Sustainable Manufacturing. Cham: Springer International Publishing; 2017.

[40] Regulation (EC) No 1893/2006 of the European Parliament and of the Council of 20 December 2006 Establishing the Statistical Classification of Economic Activities NACE Revision 2 and Amending Council Regulation (EEC) No 3037/90 as Well as Certain EC Regula. Official Journal of the European Union 2006; L393: 1-39.

[41] MASOC. Association of Mechanical Engineering and Metalworking Industries of Latvia. Riga; 2011.

[42] Commission Recommendation 2003/361/EC of 6 May 2003 Concerning the Definition of Micro, Small and Medium-Sized Enterprises. Official Journal of the European Union 2003; L124: 36-41.

[43] Warrens MJ. Similarity Coefficients for Binary Data : Properties of Coefficients, Coefficient Matrices, Multi-Way Metrics and Multivariate Coefficients. Psychometrics and Research Methodology Group, Leiden University Institute for Psychological Research, Faculty of Social Sciences, Leiden University, 2008.

[44] Bai C, Sarkis J. Improving Green Flexibility through Advanced Manufacturing Technology Investment: Modeling the Decision Process. International Journal of Production Economics 2017; 188(January 2016): 86-104. 